
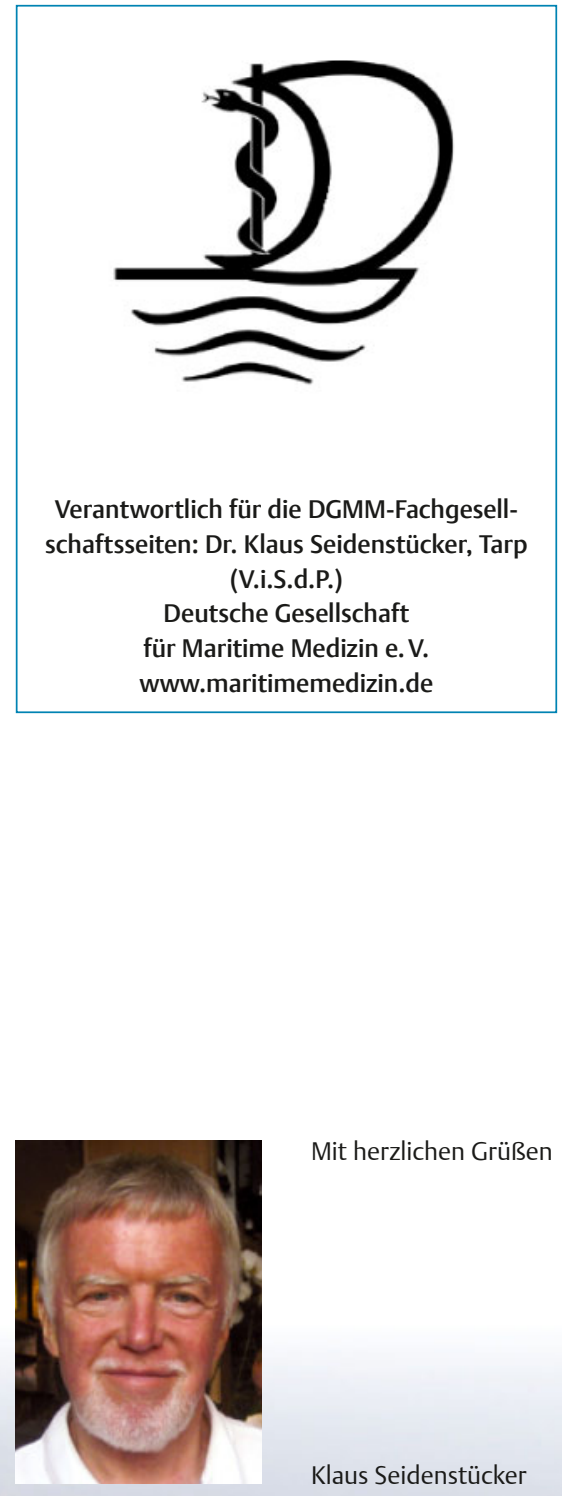

Mit herzlichen Grüßen

Klaus Seidenstücker

\section{Liebe Mitglieder,}

mit dieser Ausgabe unseres Verbandsjournals möchten wir Sie über ein drittes maritimmedizinisches Forschungsvorhaben unterrichten, an dem unsere Gesellschaft beratend teilnimmt. Diesmal eines aus unserem Hamburger Heimatinstitut! Das Vorhaben widmet sich der Erfassung von Lebens- und Arbeitsbedingungen auf Offshoreanlagen. Ziel ist die Förderung von Gesundheit und Sicherheit der Beschäftigten. Lösungen für den Schutz der Beschäftigten am Arbeitsplatz sollen entwickelt werden.

Der medizinische Studienteil will die Verringerung der physischen und psychischen Belastungen erreichen. Unzweifelhaft wird das auch seine Auswirkungen haben auf die Kriterien, die der Eignungsfeststellung von Arbeitnehmern zugrunde liegen, die auf Offshoreanlagen ihrem Broterwerb nachgehen wollen.

Deren Geburtsstunde schlug ja in unserer Gesellschaft. Unsere Empfehlungen haben inzwischen den Weg in eine Leitlinie der Arbeitsgemeinschaft der wissenschaftlichen medizinischen Fachgesellschaften gefunden. Sie leisten einen wesentlichen Beitrag zu Sicherheit und Gesundheit, definieren aber auch den beruflichen Selbstverwirklichungsrahmen der Betroffenen.

Beruhten anfänglich unsere Empfehlungen in einem völlig neuen industriellen
Umfeld auf Plausibilitätsüberlegungen der wenigen Experten, die es auf diesem Gebiet gab, so ist es jetzt an der Zeit, auf dem Hintergrund wachsender Erfahrung die für die Eignungsfeststellung formulierten Kriterien einer Evidenzprüfung zu unterziehen, um so deren Zielgenauigkeit voranzutreiben. Dies ist einer der Gründe, warum sich unsere Gesellschaft - wenngleich im überschaubaren Rahmen auch finanziell an den derzeit laufenden Untersuchungen beteiligt.

Eine Grundvoraussetzung für die Evidenzbasierung ist die möglichst vollständige und genaue Erfassung der Bedingungen, unter denen Menschen auf Offshoreanlagen leben und arbeiten sollen. Eine solche Erfassung dient gleichzeitig dem vorbeugenden Gesundheits- und Arbeitsschutz. Sie kann helfen, Belastungen und gesundheitliche Risiken zu mindern. Damit ergibt sich die Chance, den Anspruch an die Betroffenen im Rahmen der Eignungsuntersuchung zu justieren und die Untersuchungsmethodik auf ihre Aussagefähigkeit zu überprüfen.

Ich bin sicher, dass das Projekt alle Chancen hat, sich über seine gegenwärtigen thematischen, zeitlichen und finanziellen Grenzen hinaus zu entwickeln. Lesen Sie mit Interesse den folgenden Beitrag von Janika Mette. 